\title{
ANTIBACTERIAL DYEING OF POLYAMIDE USING TURMERIC AS A NATURAL DYE
}

\author{
Mohammad Mirjalili', Loghman Karimi \\ 'Department of Textile Engineering, Yazd Branch, Islamic Azad University, Yazd, Iran \\ ${ }^{2}$ Young Researchers and Elites Club, Science and Research Branch, Islamic Azad University, Tehran, Iran \\ E-mail:dr.mirjalil@iauyazd.ac.ir, mir_textile@yahoo.com
}

\begin{abstract}
:
Curcuma longa rhizome (turmeric) is a medicinal plant used for fabric and food coloration. In this study, polyamide (nylon 6.6) fabric was dyed with different mordants at various turmeric concentrations. The dyed fabric was evaluated for bacteriostatic activity against pathogenic strains of Gram-positive (Staphylococcus aureus) and Gramnegative (Escherichia coli) bacteria. The relationship between bacteriostatic activity and turmeric concentration was investigated. Durability of antibacterial activity to laundering is also discussed. Results indicate that the polyamide dyed with turmeric displayed excellent antibacterial activity in the presence of ferric sulfate, cupric sulfate, and potassium aluminum sulfate, and exhibited good and durable fastness properties.
\end{abstract}

\section{Keywords:}

Turmeric, antibacterial, bacteriostatic, mordant, polyamide, Staphylococcus aureus, Escherichia coli

\section{Introduction}

During the past decades, human health has been seriously threatened by environmental pollution, especially indoor microbiological contamination (SARS, Influenza, etc.). The statistical figures reveal that the total number of deaths caused by bacterial infection exceeds 17 million, about one-third of world-wide deaths [1]. Textiles can, thus, enhance crosscontamination by pathogenic microorganisms in environments such as home and hospitals. Textile materials provide an excellent environment for microorganisms to grow, because of their large surface area and ability to retain moisture. Microbial activity can be detrimental to textiles. It can cause unpleasant odor, lead to weakening of the substrate, discoloration, and even contribute to the spread of disease. For this reason, antimicrobials have been investigated as a finish for textiles $[2,3]$.

Antibacterial finishes are applied to textiles for three major reasons: (a) to contain the spread of disease and avoid the danger of injury-induced infection, (b) to contain the development of odor from aspiration, stains, and soil on textile materials, and (c) to contain the deterioration of textiles caused by mildew, particularly fabrics made of natural fibers [4]. Various methods, depending on the active agent and the fiber types, have been developed or are under development to confer antimicrobial activity to textiles. Many methods have been reported, such as fluorocarbon repellent finish, chemical binding of heterocyclic $\mathrm{N}$ halamine functional group to polyamide, using plasma, or immobilization of antimicrobial metallic nanoparticles on textiles $\left(\mathrm{TiO}_{2}, \mathrm{Ag}, \mathrm{Cu}, \mathrm{ZnO}\right.$, etc.) [5-14].

Although the synthetic antibacterial agents are very effective against a range of microbes, they are causes of concerns due to health hazards, action on non-target microorganisms and environmental pollution [15]. For instance, certain fluorocarbon finishes, especially those consisting of eight carbons in the perfluoro alkyl chain, can degrade to form perfluorooctanoic acid. Perfluorooctanoic acid is of environmental concern because it bioaccumulates in human body [16]. The Environmental Protection Agency has taken measures to limit the use of perfluorooctanoic acid in the industry [17].

Natural dyes are believed to be safe because of their non-toxic, non-allergic, and biodegradable nature. Many of the plants used for dye extraction are classified as medicinal, and some of them have recently been shown to possess remarkable antibacterial activity [18-22]. Curcuma longa L. known as turmeric, which is used as a coloring agent, has medicinal properties [23-25]. Curcuma longa L., which belongs to the Zingiberaceae family, originates from the Indian sub-continent and possibly neighboring areas of Southeast Asia, but it is nowadays widely grown throughout the tropics. The pigments in the colorant extracts obtained from Curcuma are collectively known as curcuminoids, the major constituent being curcumin, along with small amounts of demethoxycurcumin and bisdemethoxycurcumin (Figure 1) [26]. Turmeric has been isolated from the rhizome of $C$. longa, attributing biological activities such as antioxidant, anti-inflammatory, wound-healing, anticancer,<smiles>[R2]c1cc(/C=C/C(=O)CC(=O)/C=C/c2ccc(O)c(Br)c2)ccc1O</smiles>

$\mathrm{R} 1=\mathrm{OCH}_{3}, \mathrm{R} 2=\mathrm{OCH}_{3}-$ curcumin

$\mathrm{R} 1=\mathrm{R} 2=\mathrm{H}$ - bisdemethoxycurcumin

$\mathrm{R} 1=\mathrm{OCH}_{3}, \mathrm{R} 2=\mathrm{H}$ - demethoxycurcumin

Figure 1. Structures of curcumin and its analogs. 
anti-proliferative, antifungal, and antibacterial activity [27]. Ghoreishian and coworkers dyed silk fabric with turmeric and proved antibacterial properties to silk fabric [28]. Sundrarajan et al. modified cotton fabrics with enzymes and chitosan, and reported the enhancement of dye uptake and washing fastness of cotton fabrics dyed with turmeric [29].

Polyamide has been one of the most widely used polymers in various industries such as fiber, film, and plastic. It has major advantages of high modulus and strength, stiffness, stretch, wrinkle, and abrasion resistances [30]. However, polyamide can be easily attacked by bacteria in vivo. In this study, simultaneous antibacterial and dyed polyamide fabric was prepared by turmeric natural dyeing in the presence of various mordants, and we also focused on the antibacterial activity of treated fabrics against two common pathogenic bacteria: Escherichia coli (E. coli) and Staphylococcus aureus (S. aureus).

\section{Experimental section}

\section{Materials}

The polyamide (nylon 6.6) fabric was used with warp density 50 ends $/ \mathrm{cm}$ and weft density 28 ends $/ \mathrm{cm}$. The turmeric was purchased from Iranian traditional natural dyers. Mordants such as potassium aluminum sulfate, cupric sulfate, and ferric sulfate were purchased from Merck. Escherichia coli, a Gram-negative bacterium, was selected due to its popularity as a test organism and its resistance to common antimicrobial agents. Staphylococcus aureus, a pathogenic Gram-positive bacterium, was used because it was the major cause of crossinfection in hospitals and it is the most frequently evaluated species. Cultures of the following microorganisms were used in the study: S. aureus ATCC 25922 and E. coli ATCC 25923.

\section{$\underline{\text { Toxicity assay }}$}

Turmeric solution containing $1 \mathrm{~g} / 100 \mathrm{ml}$ was prepared and, from this stock, different concentrations $(50,75$, and 100 ppm) were prepared for testing and were finally applied to sterile 9-cm diameter Whatman No. 1 filter paper disks in Petri dishes. Then 10 surface-disinfected green grams were placed on the wetted paper. After 14 days of incubation at $27 \pm^{\circ} \mathrm{C}$, the total root growth (germination) was measured and compared with the control (untreated sample) and was expressed as root growth inhibition percentage [31].

\section{Dyeing procedure}

To study the relationship between dye concentration and antimicrobial activity, $100 \%$ polyamide fabrics were dyed with $5,10,20$, and $30 \%$ turmeric on weight of fabric (OWF) with potassium aluminum sulfate, cupric sulfate, and ferric sulfate mordants, and un-mordant. The polyamide fabric was dyed in an AHIBA dyeing system with turmeric dye. The dye bath comprised dye, $1 \%$ acetic acid, and $3 \%$ mordant. The liquor ratio was kept at $40: 1$. The temperature was raised to $100^{\circ} \mathrm{C}$ by a thermal gradient of $2^{\circ} \mathrm{C} / \mathrm{min}$, and dyeing operation continued for $60 \mathrm{~min}$.

\section{Color measurements}

The dyed polyamide fabrics were individually tested for their color strength. The color strength $(K / S)$ values of the dyed fabrics were instrumentally determined by reflectance spectrophotometer (BYK-Gardner, India, with CIELAB 1976 color space and D65-light source) with Kubelka-Munk equation as follows:

$$
\frac{K}{S}=\frac{(1-R)^{2}}{2 R}
$$

where $R$ is the reflectance of the dyed fabric at the maximum absorption wavelength, $S$ is the scattering coefficient, and $K$ is the absorption coefficient of the dyed fabrics.

\section{Antibacterial test}

Antibacterial activity against Gram-positive bacteria (S. aureus) and Gram-negative bacteria (E. coli) was tested quantitatively by AATCC Test Method 100-1999. The number of viable bacterial colonies on the agar plate before and after dyeing was counted and the results reported as percentages of bacteria reduction according to

$$
R=(B-A) / B \times 100
$$

where $R$ denotes the percentage of reduction of microbial population; $B$ is the absorbance of the media inoculated with microbes and un-dyed fabric; and $A$ shows the absorbance of the media inoculated with microbes and dyed fabric.

\section{Durability to laundering}

Durability of antimicrobial activity to washing is one of the major concerns of textile researchers and users because textiles are subjected to frequent laundering. The treated samples with $30 \%$ concentration of turmeric were washed under condition of the ISO 105-CO2 Test Method to determine the bacteriostatic effect of fabrics after 1, 5, 10 and 20 cycles of laundering.

\section{Results and discussion}

\section{Toxicity assay}

The results demonstrate that turmeric at different concentrations caused no inhibition to germination and root growth to the green grams and a growth rate of more than $90 \%$ was observed. The untreated and treated green grams were almost equal in their germination and growth rate. Thus, the turmeric was found to be non-toxic.

\section{Color strength of polyamide fabrics}

The majority of natural dyes need a mordant in the form of a metal salt to create an affinity between the fiber and the pigment. These metals form a ternary complex on one side with the fiber and on the other side with the dye. Such a strong coordination tendency enhances, the interaction between the fiber and the dye, resulting in high dye uptake. 
Figure 2 shows the graph of treated samples K/S dyed by turmeric (20\%). The result of dyeing samples shows that using mordants considerably increased dye absorption leading to higher $K / S$ values in case of mordanted samples than unmordanted ones. Ferric sulfate mordant was found to have the most prominent effect on color strength.

\section{Bacteriostatic activity}

Table 1 shows the photographs of bacterial growths upon treated polyamide fabrics. Figures 3 and 4 exhibit comparative diagrams of bacteriostatic activity results for the treated sample in the presence of $E$. coli and $S$. aureus bacteria. Curcumin

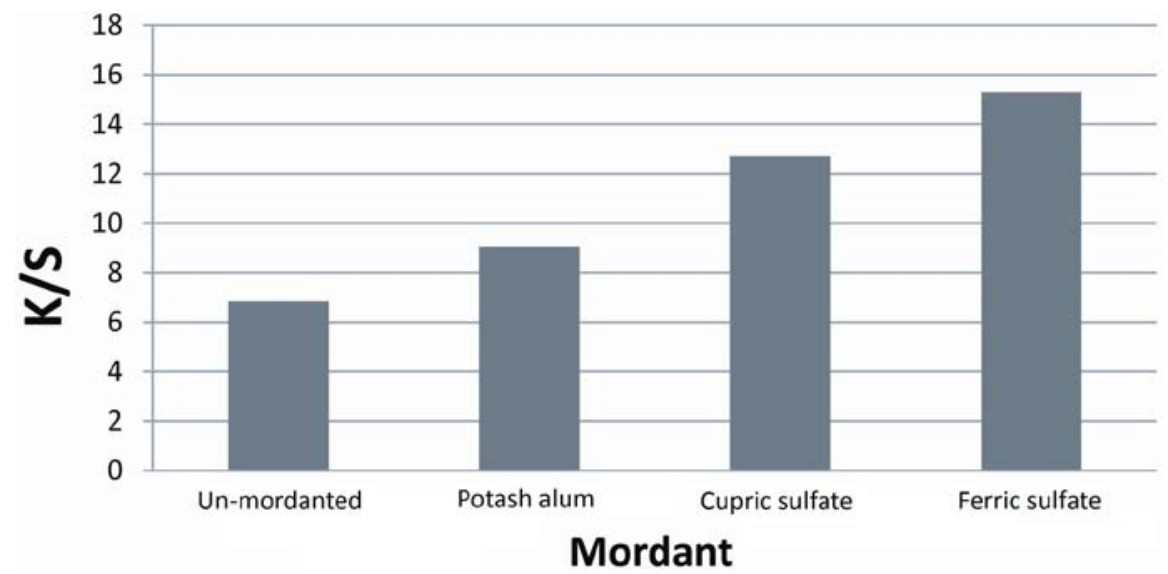

Figure 2. K/S graph of the dyed polyamide fabric samples with $20 \%$ turmeric (OWF).

Table 1. Photographs showing the growth of $S$. aureus and E. coli bacteria upon treated samples.

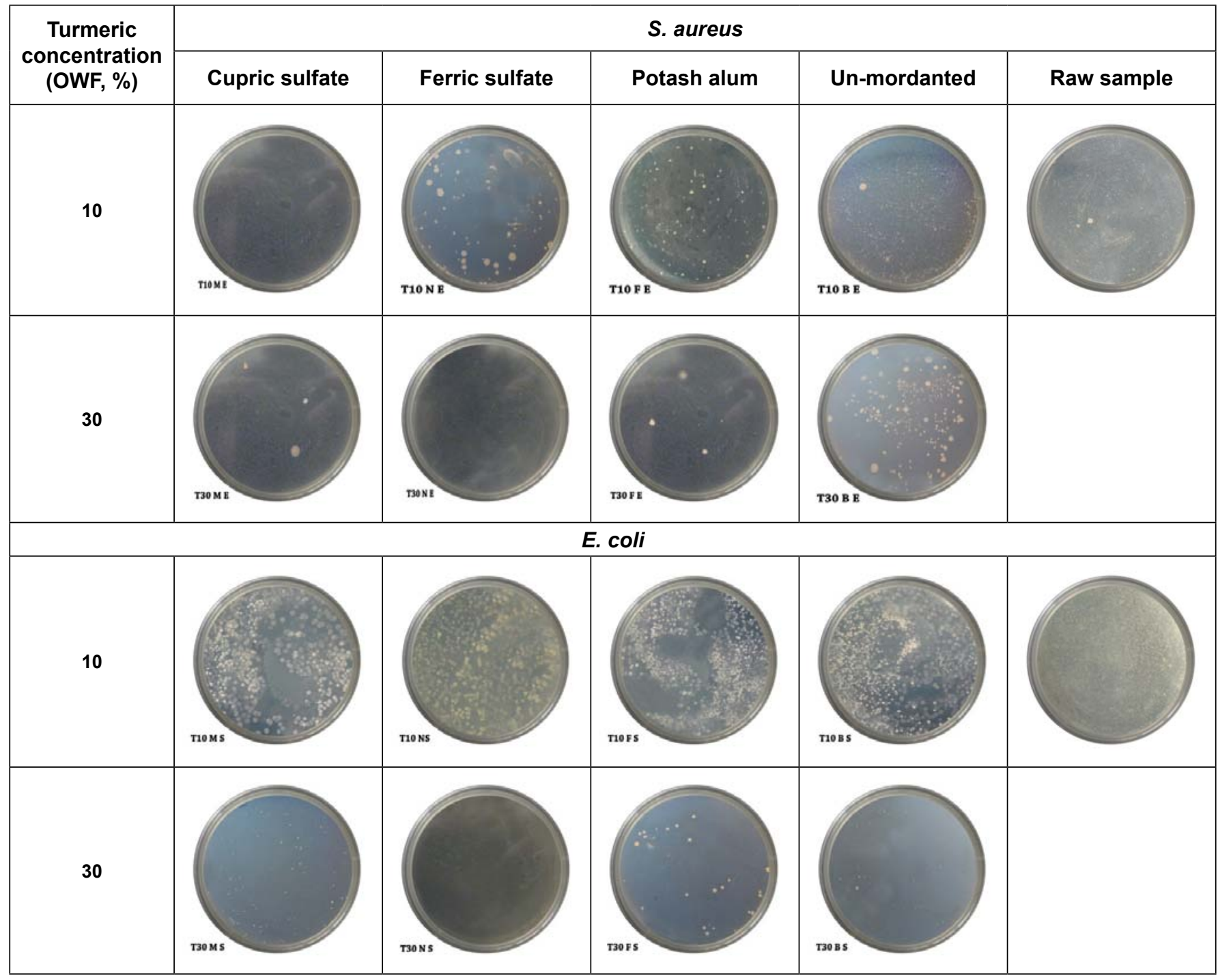




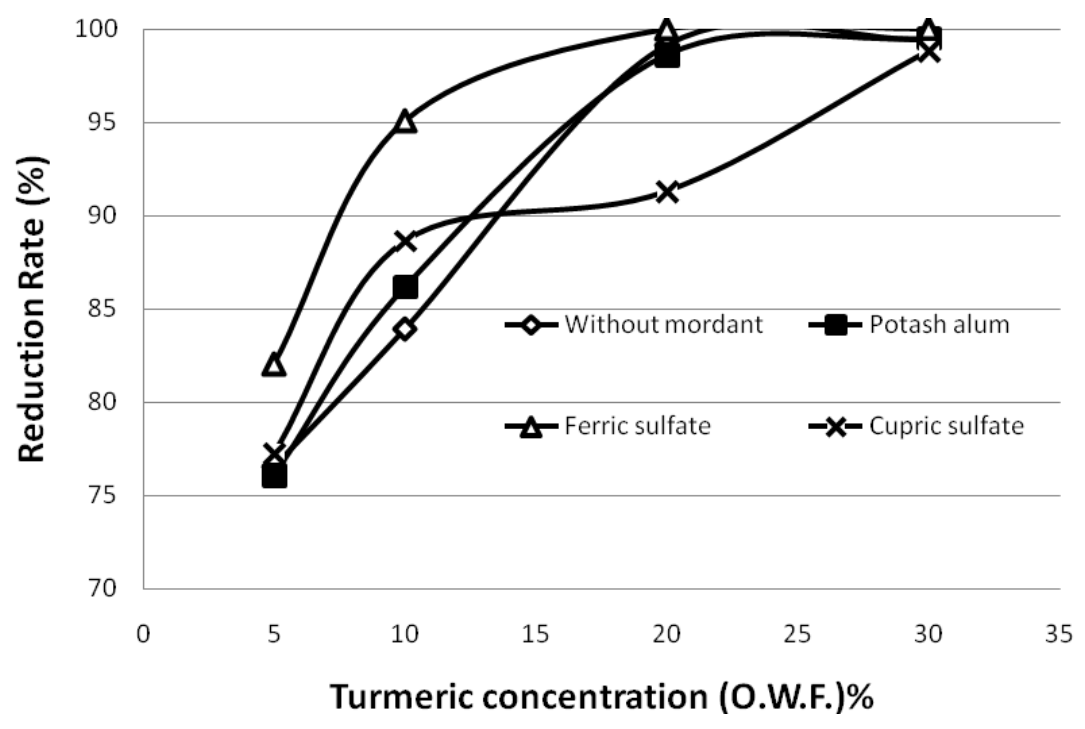

Figure 3. Antimicrobial activity of dyed polyamide samples with turmeric in the presence and absence of mordant against $S$. aureus.

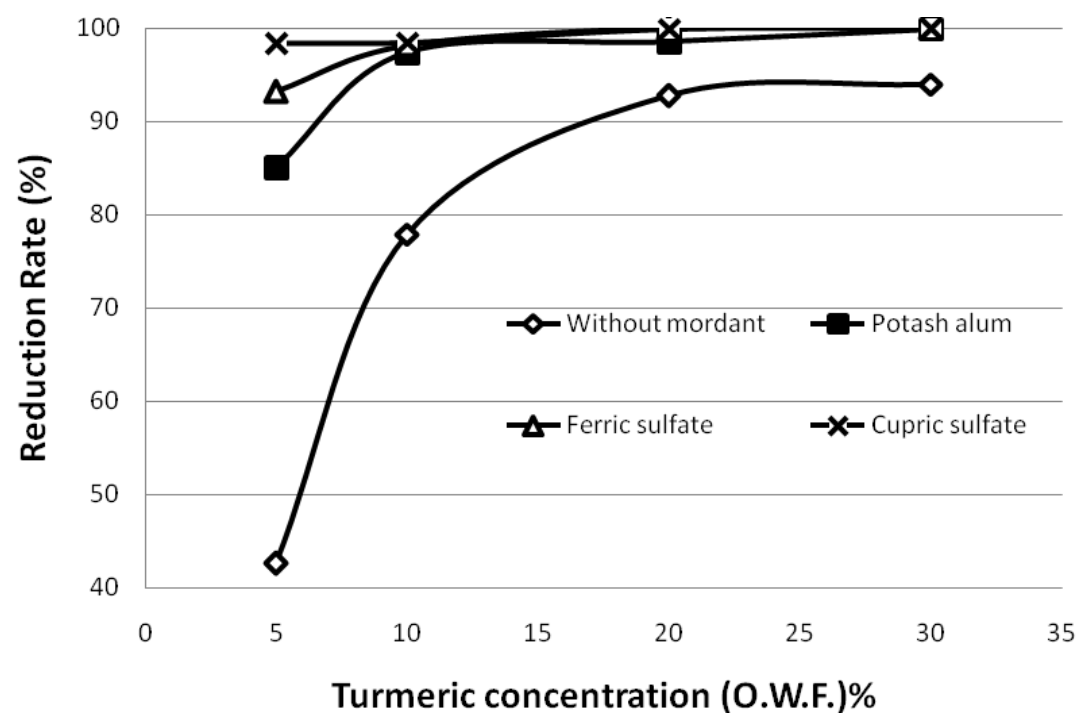

Figure 4. Bacteriostatic activity of dyed polyamide samples with turmeric in the presence and absence of mordant against $E$. coli.

found in turmeric affects RNA and DNA of microorganisms and their fights.

The bacteriostatic activity of treated fabrics was ranked as ferric sulfate $>$ cupric sulfate $>$ potassium aluminum sulfate $>$ unmordant against $S$. aureus and cupric sulfate $>$ ferric sulfate $>$ potassium aluminum sulfate $>$ un-mordant against E. coli.

Based on the obtained results, specimens showed a better efficiency against $E$. coli in comparison with $S$. aureus. This can be explained by the difference between thicknesses of the cell walls. Staphylococcus aureus has a thicker cell wall [32]. They also showed that using mordant had better bacteriostatic activity. It is well known that the metallic salts used as mordants exhibit toxic effects against the pathogens.

Natural dyes are non-toxic, biodegradable, and do not cause pollution and wastewater problems, while synthetic dyes have been known to cause health hazards due to their carcinogenic effects. Hence, it is suggest that the turmeric dye can be used for dyeing polyamide as an alternative to the very expensive, synthetic, and toxic antibacterial agents.

\section{Washing fastness properties}

Textiles are subjected to frequent washing, rubbing, and sweating during their use and the requirement of durability is a very important parameter. Figures 5 and 6 depict the durability of antibacterial activity after repeated home launderings. As shown, the antibacterial activity reduced with increased number of washing cycles. The inhibition rate of treated sample un-mordant was more reduced than the treated sample with mordant after laundering.

\section{Conclusion}

This is the first report where turmeric, used in polyamide dyeing, has been shown as a source of a natural, non-toxic dye. This 


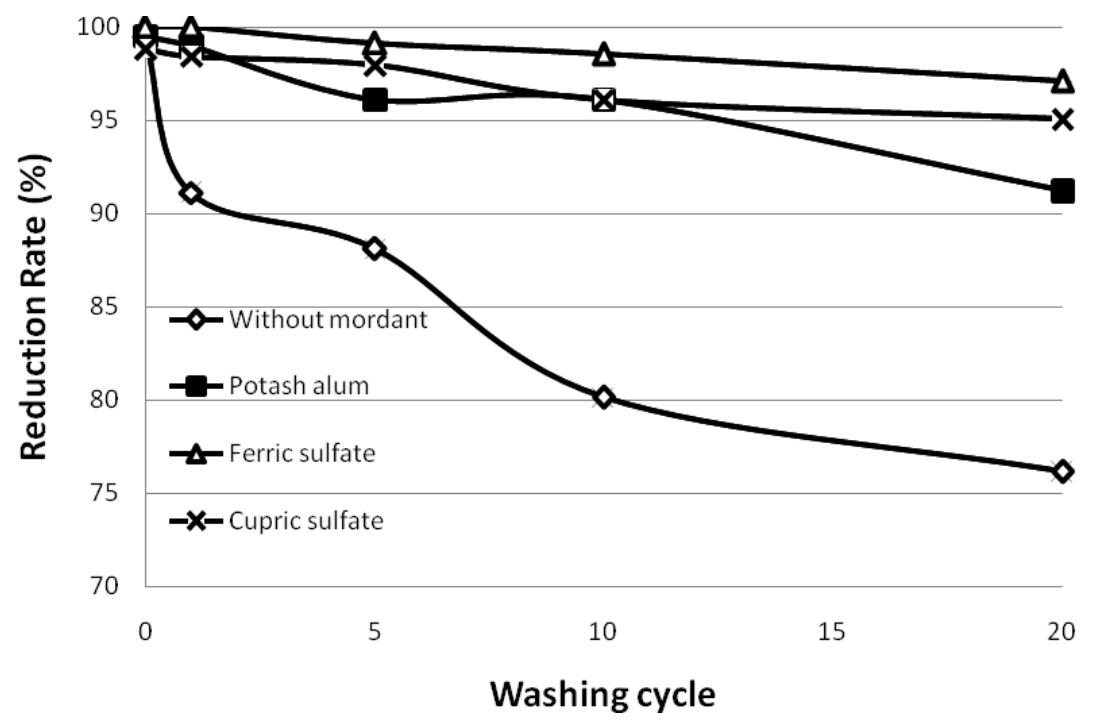

Figure 5. Bacteriostatic activity of dyed polyamide samples with turmeric in the presence and absence of mordant against $S$. aureus after laundering.

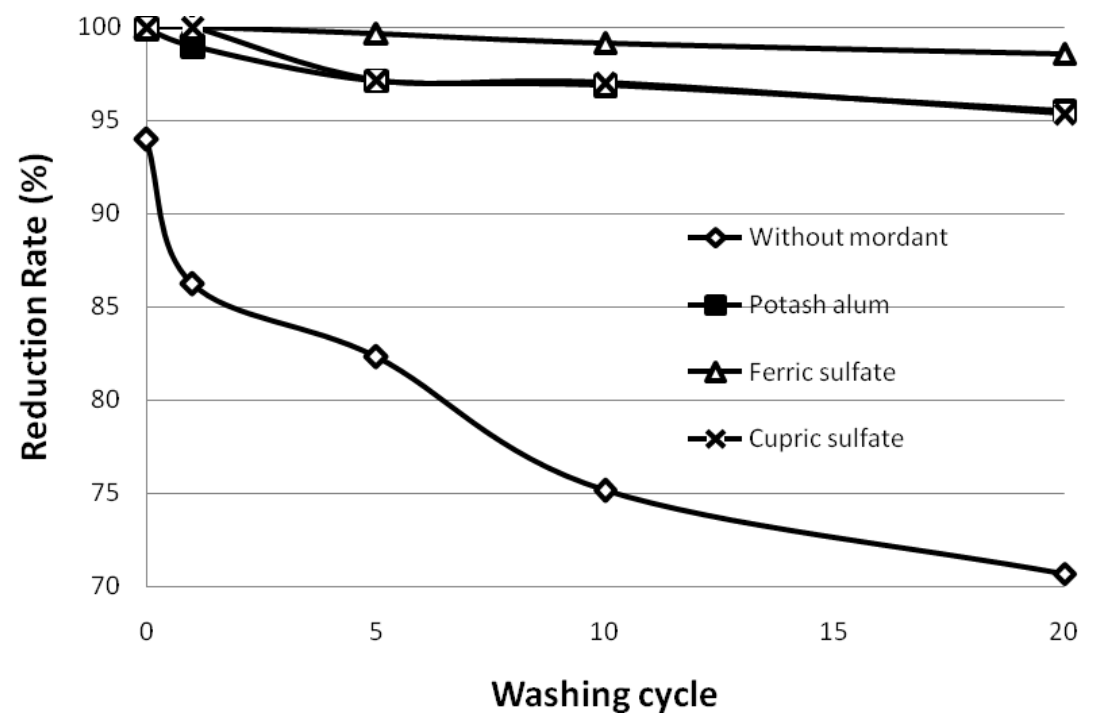

Figure 6. Bacteriostatic activity of dyed polyamide samples with turmeric in the presence and absence of mordant against $E$. coli after laundering.

research was conducted to introduce an effective natural dye to produce an ideal antibacterial polyamide fabric. A common dyeing process provides polyamide with color and antibacterial properties. Since the dyeing process and bacteriostatic finishing have been conducted in one step and do not require an additional step, this method is cost-effective. Natural-dyed

\section{References}

[1] Qian T., Su H. and Tan T., 2011, The bactericidal and mildew-proof activity of a $\mathrm{TiO}_{2}$-chitosan composite, Journal of Photochemistry and Photobiology A: Chemistry, vol. 218, pp. 130-136.

[2] Purwar R. and Joshi M., 2004, Recent developments in antimicrobial finishing of textiles - a review, AATCC Review, vol. 4(3), pp. 22-25.

[3] Schindler W.D. and Hauser P.J., 2004, Chemical Finishing of Textiles, Woodhead, England, Cambridge. polyamide presented a strong bacteriostatic activity against two well-known pathogenic bacteria $S$. aureus and E. coli. Turmeric is more effective against $E$. coli than $S$. aureus. Moreover, using mordant had better bacteriostatic activity. The bacteriostatic activity of turmeric mordant-finished polyamide is more durable to home laundering than the un-mordanted ones. 
[7] Lin J., Winkelman K., Worley S.D., Broughton R.M. and Williams J.F., 2001, Antimicrobial treatment of nylon, Journal of Applied Polymer Science, vol. 81, pp. 943-947.

[8] Mirjalili M. and Karimi L., 2013, The impact of nitrogen low temperature plasma treatment upon the physicalchemical properties of polyester fabric, Journal of The Textile Institute, vol. 104(1), pp. 98-107.

[9] Khalil-Abad M.S., Yazdanshenas M.E. and Nateghi M.R., 2009, Effect of cationization on adsorption of silver nanoparticles on cotton surfaces and its antibacterial activity, Cellulose, vol. 16, pp. 1147-1157.

[10] Armelao L., Barreca D., Bottaro G., Gasparotto A., Maccato C., Maragno C., Tondello E., Stangar U., Bergant M. and Mahne D., 2007, Photocatalytic and antibacterial activity of $\mathrm{TiO}_{2}$ and $\mathrm{Au} / \mathrm{TiO}{ }_{2}$ nanosystems, Nanotechnology, vol. 18, pp. 375709-37516.

[11] Nakashima T., Sakagami Y., Ito H. and Matsuo M., 2001, Antibacterial activity of cellulose fabrics modified with metallic salts, Textile Research Journal, vol. 71(8), pp. 688-694.

[12] Karimi L., Mirjalili M., Yazdanshenas M.E. and Nazari A., 2010, Effect of nano $\mathrm{TiO}_{2}$ on self-cleaning property of cross-linking cotton fabric with succinic acid under UV irradiation, Photochemistry and Photobiology, vol. 86, pp. 1030-1037.

[13] Wong M., Chu W., Sun D., Huang H., Chen J., Tsai P., Lin N., Yu M., Hsu S., Wang S. and Chang H., 2006, Visible-light-induced bactericidal activity of a nitrogendoped titanium photocatalyst against human pathogens, Applied Environmental Microbiology, vol. 72(9), pp. 6111-6116.

[14]Dubas S.T., Kumlangdudsana P. and Potiyaraj P., 2006, Layer-by-layer deposition of antimicrobial silver nanoparticles on textile fibres, Colloids and Surfaces $A$ : Physicochemical and Engineering Aspects, vol. 289, pp. 105-109.

[15] Khan M.I., Ahmad A., Khan S.A., Yusuf M., Shahid M., Manzoor N. and Mohammad F., 2011, Assessment of antimicrobial activity of Catechu and its dyed substrate, Journal of Cleaner Production, vol. 19, pp. 1385-1394.

[16] Armitage J.M., Macleod M. and Cousins I.T., 2009, Comparative assessment of the global fate and transport pathways of long-chain perfluorocarboxylic acids (PFCAs) and perfluorocarboxylates (PFCs) emitted from direct sources, Environmental Science Technology, vol. 43(15), pp. 5830-5836.

[17] U.S. Environmental Protection Agency, PFOA Stewardship Program, 2010/2015.

[18] Ali S., Hussai T. and Nawaz R., 2009, Optimization of alkaline extraction of natural dye from Henna leaves and its dyeing on cotton by exhaust method, Journal of Cleaner Production, vol. 17, pp. 61-66.
[19] Mirjalili M., Nazarpoor K. and Karimi L., 2011, Eco-friendly dyeing of wool using natural dye from weld as co-partner with synthetic dye, Journal of Cleaner Production, vol. 19, pp. 1045-1051.

[20] Prusty A.K., Das T., Nayak A. and Das N.B., 2010, Colourimetric analysis and antimicrobial study of natural dyes and dyed silk, Journal of Cleaner Production, vol. 18, pp. 1750-1756.

[21] Singh R., Jain A., Panwar S., Gupta D. and Khare S.K., 2005, Antimicrobial activity of some natural dyes, Dyes and Pigments, vol. 66, pp. 99-102.

[22] Mirjalili M., Nazarpoor K. and Karimi L., 2011, Extraction and identification of dye from walnut green husks for silk dyeing, Asian Journal of Chemistry, vol. 23(3), pp. 10551059.

[23] Han S. and Yang Y., 2005, Antimicrobial activity of wool fabric treated with curcumin, Dyes and Pigments, vol. 64, pp. 157-161.

[24] Hao X. and Lu Y.H., 2011, Dyeing properties of tussah silk fabric with indigo naturalis and turmeric, Advanced Materials Research, vol. 331, pp. 352-355.

[25] Ujjin S. and Jantip S., 2012, Study on the dyeing properties of poly(lactic acid) and silk yarns with natural dyes, Advanced Materials Research, vol. 486, pp. 384-387.

[26] Bechtold T. and Mussak R., 2009, Handbook of Natural Colorants. John Wiley \& Sons Ltd.

[27] Barik A., Mishra B., Kunwar A., Kadam R.M., Shen L., Dutta S., Padhye S., Satpati A.K., Zhang H. and Priyadarsini K.I., 2007, Comparative study of copper(II): curcumin complexes as superoxide dismutase mimics and free radical scavengers, European Journal of Medicinal Chemistry, vol. 42, pp. 431-439.

[28] Ghoreishian S.M., Maleknia L., Mirzapour H. and Norouzi M., 2013, Antibacterial properties and color fastness of silk fabric dyed with turmeric extract, Fibers and Polymers, vol. 14(2), pp. 201-207.

[29] Sundrarajan M., Rukmani A., Gandhi R.R. and Vigneshwaran S., 2012, Eco friendly modification of cotton using enzyme and chitosan for enhanced dyeability of Curcuma longa, Journal of Chemical and Pharmaceutical Research, vol. 4(3), pp. 1654-1660.

[30] Lewin M., 2007, Handbook of Fiber Chemistry, third edition, CRC Press.

[31] Nagia F.A. and EL-Mohamedy R.S.R., 2007, Dyeing of wool with natural anthraquinone dyes from Fusarium oxysporum, Dyes and Pigments, vol. 75, pp. 550-555.

[32] Nadtchenko V.A., Rincon A.G., Stanca S.E. and Kiwi J., 2005, Dynamics of E. colimembrane cell peroxidation during $\mathrm{TiO}_{2}$ photocatalysis studied by ATR-FTIR spectroscopy and AFM microscopy, Journal of Photochemistry Photobiology A:Chemistry, vol. 169, pp. 131-137. 